\title{
Asymptomatic Bacteriuria among Pregnant Women Attending Antenatal Clinic at the Akuapem North District of the Eastern Region of Ghana
}

\author{
Eli Dzandu ${ }^{1}$, Ernest Kenu ${ }^{1}$, Aquel Rene Lopez ${ }^{2 *}$, Sampson Mark Amegayie ${ }^{3}$, Clement \\ Amdor $^{4}$, Tanko Rufai ${ }^{5}$, Julia Kwakoa Karikari ${ }^{6}$ \\ ${ }^{1}$ School of Public Health, University of Ghana, Ghana \\ ${ }^{2}$ Department of Haematology, Tetteh Quarshie Memorial Hospital, Mampong, Ghana \\ ${ }^{3}$ Librarian, University of Ghana, Ghana \\ ${ }^{4}$ Department of Bacteriology, Tamale Teaching Hospital. Tamale, Ghana \\ ${ }^{5}$ Medical Laboratory Scientist, Koforidua Policlinic, Koforidua \\ ${ }^{6}$ Department of Obstetrics and Gynaecology Sinel Specialist Hospital, Tema, Ghana
}

\begin{abstract}
Asymptomatic bacteriuria is a condition in which urine culture reveals the presence of more than $10^{5}$ bacteria per millilitre but without the patient showing signs and symptoms of urinary tract infection (UTI). In many of the health care facilities in Ghana, routine screening for ASB among pregnant woman is not done despite overwhelming evidence clearly demonstrating its benefits in preventing UTI and the associated adverse pregnancy outcome. It is a common problem in pregnant women, which usually results in maternal and fetal complications. The majority of the participant were in the age range of 25 years to 34 years, and all the participants had basic education. Out of the 134 sterile urine samples cultured, 11 of the participants had bacteria isolated from their urine, given a prevalence of $8.2 \%$. Escherichia coli were $63.6 \%$, Nitrofurantoin was $81.8 \%$ sensitive to all bacteria isolated, and Cotrimoxazole was the most resistant antibiotic with $72.7 \%$. Factors associated with ASB in Akuapem North District were toilet facility, multiple pregnancy, and any medical condition, which were statistically significant at the bivariate analysis level. After adjusting these factors with the multiple logistics regression, only multiple pregnancy was statistically significant. The study revealed an $8.2 \%$ prevalence of ASB among pregnant women with E. coli, the predominate bacteria with $63.6 \%$. Nitrofurantoin, $81.8 \%$ sensitive, and Cotrimoxazole was the most resistant antibiotics with $72.7 \%$. Multiple pregnancy was associated with Asymptomatic bacteriuria among pregnant women at Akuapem North District.
\end{abstract}

Keywords: Asymptomatic Bacteriuria, Pregnant Women, Urine Culture, Urinary Tract Infection.

\section{Introduction}

Asymptomatic bacteriuria is a condition in which urine culture reveals the presence of more than $10^{5}$ colony forming unite of bacteria per millilitre $(\mathrm{CFU} / \mathrm{mL})$, but the client is showing no signs and symptoms of urinary tract infection [1].

An early study by [2] revealed that the apparent reduction in immunity of pregnant women appears to encourage the growth of both commensal and pathogenic microorganisms. During pregnancy, there is a physiological increase in plasma volume and a decrease in urine concentration up to about $70 \%$ that developed glycosuria which encourages bacteria growth in the urine [3]. Again, in their study, although all women are prone to the development of UTIs, pregnant women are at increased risk because of the numerous changes in the woman's body caused by pregnancy. In support of [3] findings, [4] also came out that 
pregnant women have hormonal and anatomical changes that contribute to ureteral dilatation and urinary stasis. These changes include shortness of the urethra and difficulty with hygiene due to a distended belly that increases UTI frequency in pregnant women.

To [5], women with Asymptomatic bacteriuria show a variable degree of the local urinary, immune response. This is almost onethird to half of the elderly women with Asymptomatic bacteriuria having elevated antibody levels compared with non-bacteriuria women. Further findings of [5] revealed that Asymptomatic bacteriuria, which is urinary cytokines, has been shown to be more frequently present in women when they become pregnant. In Africa, [6] reported that the prevalence of Asymptomatic bacteriuria among pregnant women and their effect on the reduction in immunity has increased risk factors such as infection of the foetus.

In Ghana, [7] reported that the prevalence of Asymptomatic bacteriuria was associated with sexual activity during pregnancy but not with sexual frequency. [7] also disagree that urinary infection does not affect the foetus being carried but reported that the commonest organism isolated was Enterococcus spp, although the Enterobacteriaceae formed the majority of isolated organisms. [7] also contended that nitrofurantoin was the antibiotic with the highest sensitivity to all the isolated organisms." [8] and [9] in their studies mentioned that pregnancy increases the progression from asymptomatic to symptomatic bacteriuria, leading to pyelonephritis and obstetric outcomes such as prematurity, low birth weight, and higher foetal mortality rates. [8] again added that the adverse effects of Asymptomatic undiagnosed bacteriuria on mother and child have made researchers to recommend routine urine culture for all pregnant women attending the antenatal clinic to prevent mother and child from any form of complication that may arise due to infection. Briefly, extensive work has not been done when it comes to Asymptomatic bacteriuria and its associated factors in the study area of Akuapem North District. Therefore, this study aims to screen for Asymptomatic bacteriuria and its antibiotic susceptibility patterns of the isolated bacteria among antenatal women that visited the health care facilities at the Akuapem North District.

\section{Materials and Methods}

The research employed a cross-sectional study between May to June 2019 to collect both qualitative and quantitative data on pregnant women attending antenatal clinics at Akuapem North District.

\section{Study Site}

The study was conducted at Akuapem North District, which is located at the south-eastern part of the Eastern Region, which is about $58 \mathrm{~km}$ from Accra, the capital city of Ghana. The Akuapem North Municipal shares boundaries to the northeast with Yilo Krobo, north with New Jauben Municipal, southeast with Dangbe West, southwest with Akuapem South District, and in the west with Suhum-Kraboa-Coaltar District. The district covers a land area of about $450 \mathrm{sq}$. $\mathrm{km}$ representing 2.3 percent of the total area of the Eastern Region and has about 230 settlements [9]. 


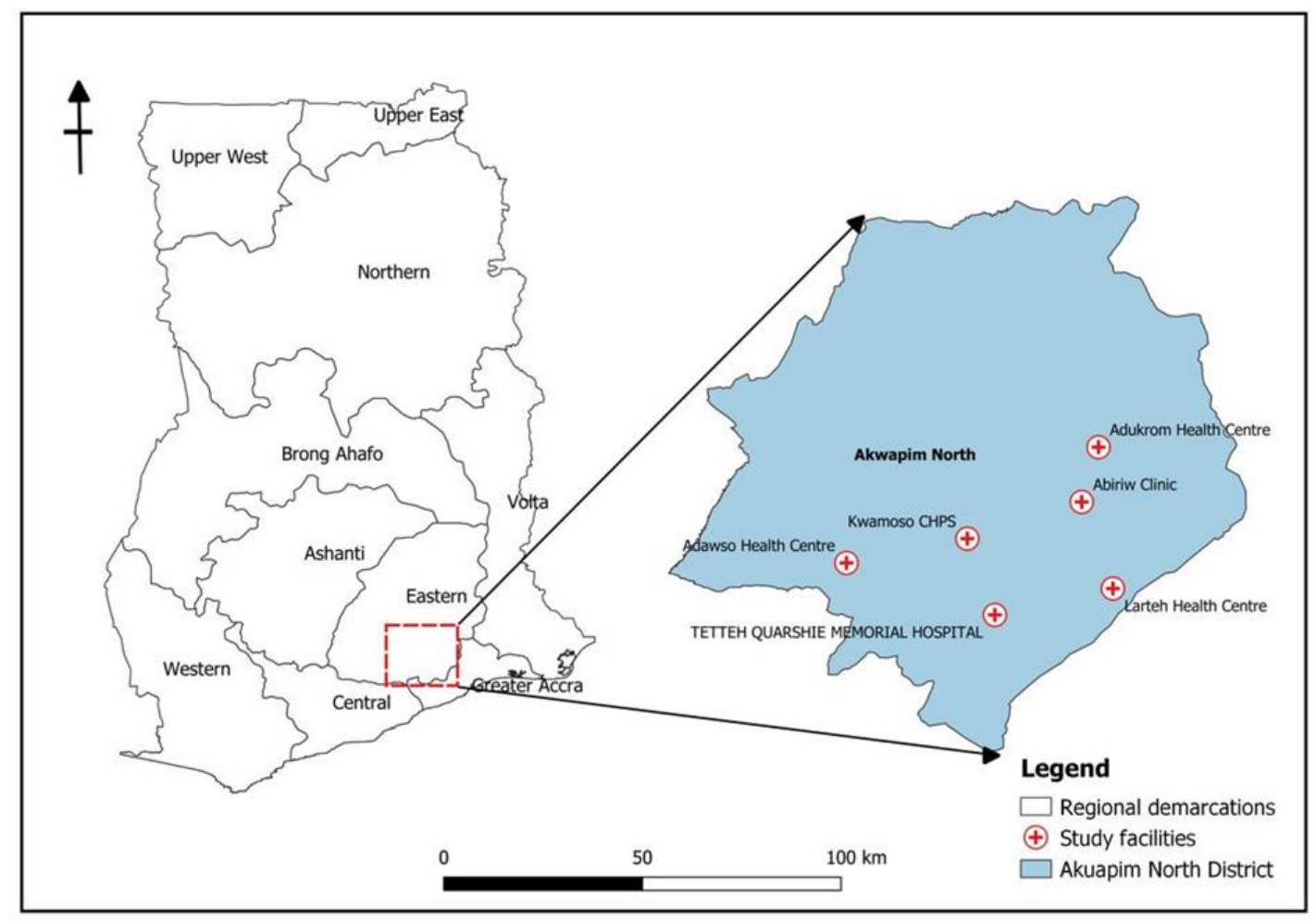

Figure 1. Map of Akuapem North

\section{Study Population}

The study population was all pregnant women who were attending antenatal clinics at any of the six selected health facilities at Akuapem North District from May to June 2019.

\section{Sampling}

\section{Sample Size Determination}

The sample size was calculated from Cochran's formula.

$$
n=Z^{2} p(1-p) / e^{2}
$$

Where $\mathrm{n}$ is the minimum sample size, $\mathrm{Z}$ is the standard $\mathrm{z}$ score that corresponds with a $95 \%$ confidence interval, which is $1.96, \mathrm{p}$ is the proportion of pregnant women with ASB and e is the allowable error margin set at $5 \%$.

$$
n=Z^{2} p(1-p) / e^{2}
$$

this implies that,

\section{$\mathrm{Z}=95 \% \mathrm{CI}$ is 1.96}

$\mathrm{p}=$ proportion of pregnant women with Asymptomatic bacteriuria in Akuapem North District. In Akuapem North District, the proportion of is u Figure 2: Map of Akuapem
North known but a similar study was carried out at Komfo Anokye with the prevalence of $7.3 \%$ [10] was used for the calculation of the minimum sample size for the study.

$$
\begin{aligned}
& \mathrm{p}=7.3 \%=0.073 \\
& \mathrm{e}=5 \%=0.05 \\
& \quad n=Z^{2} p(1-p) / e^{2} \\
& =1.96^{2} * 0.073(1-0.073) / 0.05^{2}=3.8416 * \\
& 0.073(0.927) / 0.0025 \\
& =3.8416 * 0.073(0.927) / 0.0025=3.8416 * \\
& 0.067671 / 0.0025 \\
& =\quad 3.8416 \quad * \quad 0.067671 / 0.0025 \\
& =0.2599649136 / 0.0025 \\
& =103.985 \sim 104 \text { participants. }
\end{aligned}
$$

\section{Sampling Method}

A five-year antenatal attendance book was used to calculate the mean attendance for each of the 23 health facilities in the district. Six health facilities were selected for the study based on the highest number of antenatal attendances. Samples were proportionately allocated to the six health facilities based on their five-year attendance. Those who consented to be part of the study had their urine specimens screened 
with the routine urine examination test to exclude those with protein, leucocyte, nitrate, glucose, and pus cells in their urine. Based on the number that was negative for protein, leucocyte and nitrate, and pus cells in their urine, the pregnant women were randomly selected by picking YES or NO, which was written on pieces of paper, folded, and put into a bowl. All those who picked YES were selected for the study. In instances where only a pregnant woman's result was negative on a particular day, that person was selected automatically for the study. The procedure was repeated on another antenatal day for those who were not already screened until they require a number from each stratum was gotten.

\section{Selection of Participants}

Routine urine examination was used as a baseline after they had satisfied the inclusion criteria and consented to be part of the study. Urine specimens from the pregnant women were collected and screened for the presence of protein, nitrate, glucose, leucocytes, and pus cell. All those who were negative after the routine urine examination test were randomly selected by picking YES or NO to give an equal chance of been included into the study.

\section{Data Collection Techniques and Tools}

\section{Review of Patients Records}

Maternal and child health record book (antenatal book) was used to retrieve information on clinical and pregnancy history such as gestational age, previous delivery with any birth defects, any medical condition, and outcome of the previous delivery.

\section{Laboratory Analysis}

\section{Culture and Antimicrobial Susceptibility}

Each urine specimen was well mixed by swirling the container. A sample was plated (cultured) in a labelled petri dishes containing a media of Cystine Lactose Electrolyte Deficient (CLED) and 5\% sheep blood agar media for the primary isolation of uropathogen using a sterile calibrated wire loop $(0.002 \mathrm{~mL})$ to inoculate a loopful of urine onto a half plate of each of the agars.

The culture plates were incubated between $35^{\circ} \mathrm{C}-37^{\circ} \mathrm{C}$ aerobically for $18-24$ hours. When there is bacterial growth after 18-24 hours of incubation morphological identification, biochemical test, colony count, and sensitivity were performed.

\section{Data Analysis}

The data was analysed using STATA software version 15 .

\section{Results and Discussion}

134 urine specimens were analyzed from pregnant women in six selected health facilities in the Akuapem North District who came for their antenatal clinic during the period of the study. Routine urine examination was performed, and those pregnant women whose results were negative for protein, leucocytes, nitrite, glucose, and pus cells less than 4 HPF and consented were enrolled in the study. A microbiological culture method was performed to determine the proportion of Asymptomatic bacteriuria among pregnant women at Akuapem North District. The ages of participants ranged from a minimum of 17 years to 43 years with an average age of 29.9 years (SD \pm 6.3 ). The majority of the pregnant women, 72 representing $53.7 \%$, were in the age range of 25-34 years, and $24.6 \%$ pregnant women were above 35 years.

All participants and the fathers of the inborn babies (foetus) had some level of education. 73 pregnant women representing $54.5 \%$, had basic education, while 79 representing $58.9 \%$ of the baby's (foetus) father, had advanced education. More than $78 \%$ of the participants were working at the time of the study, but only 17 , representing $12.7 \%$, earned a monthly income above one thousand Ghana cedis. More than $50 \%$ of the pregnant woman were married, 57(42.5\%) were co-habiting, and the remaining 5 representing $3.8 \%$, were single. 55 of the respondents representing $41.0 \%$, were yet to have their first 
child/twins, and 18 representing $13.5 \%$, had a total family size of more than five. The prevalence of Asymptomatic bacteriuria among the study sample was $8.2 \%(4.2 \%-14.2 \%)$.

In this study, urine culture and sensitivity, which is the gold standard, was randomly ran for 134 pregnant women who visited any of the six selected health facilities in the Akuapem North District. 134 pregnant women were screened with the current technique routine urine examination that is normally employed at these health facilities. A routine urine examination method was performed, and the results for those who were negative were assumed free from bacterial infection. However, a sterile urine container was given to all those participants to produce another urine specimen for culturing. 11 turned up with bacteria growth representing 8.2\% CI (4.2-14.2) that were negative from the earlier test performed. This, therefore, meant that they actually had Asymptomatic bacteriuria. Figure 2 below gives the pictorial view of the isolated bacteria. In order to check how significant this proportion of the number of pregnant women who actually had Asymptomatic bacteriuria a binomial test was run as shown in Table 1.

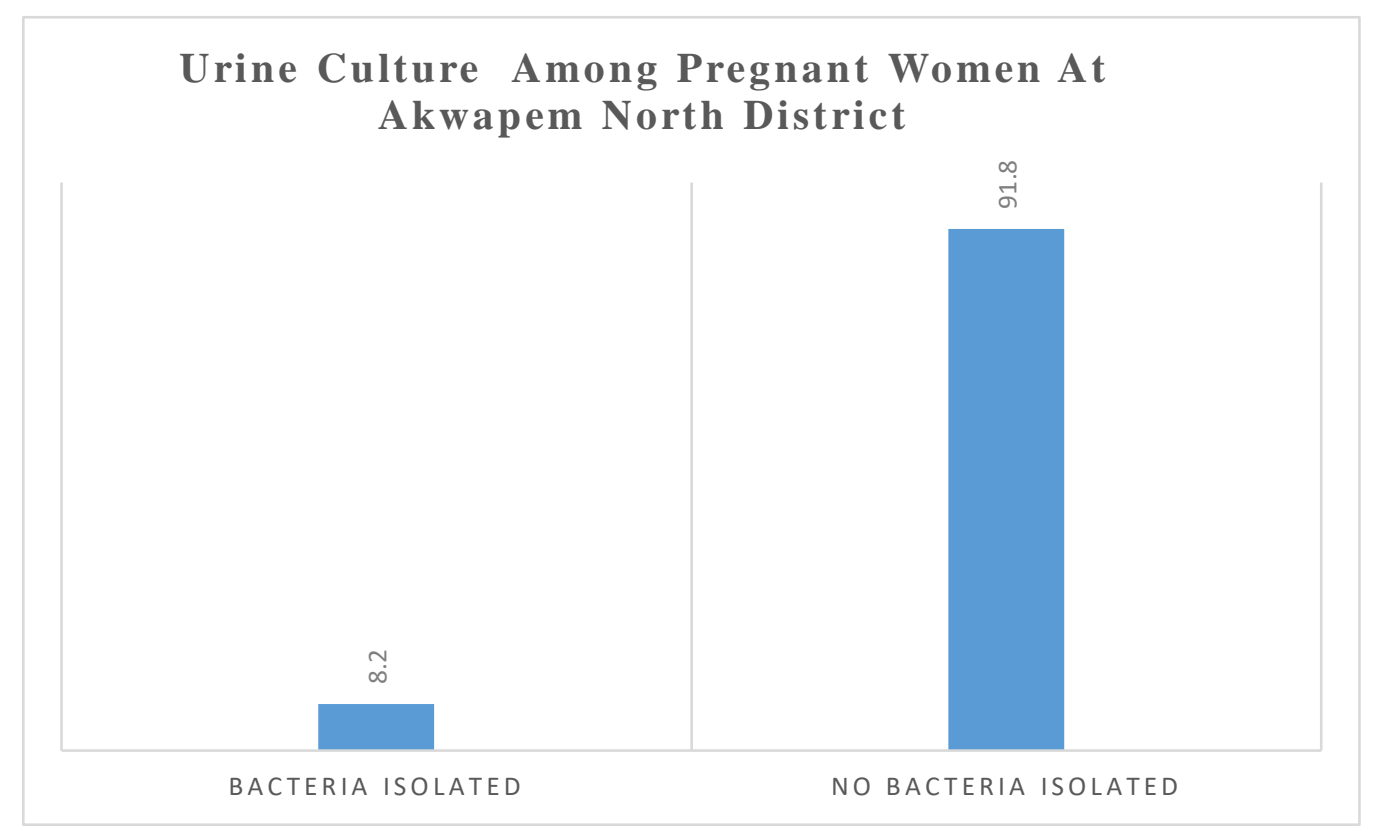

Figure 2. Urine Culture among Pregnant Women at Akuapem North District

Table 1. Binomial Test for Sample Proportion

\begin{tabular}{|l|l|l|l|l|l|c|}
\hline \multicolumn{3}{|c|}{ Category } & N & Observed Prop. & Test Prop. & P-value \\
\hline \multirow{3}{*}{ Bacteria growth } & Group 1 & No bacteria growth & 123 & 0.918 & .999 & $0.000^{\mathrm{a}}$ \\
\cline { 2 - 7 } & Group 2 & Bacteria Growth & 11 & 0.082 & - & - \\
\cline { 2 - 7 } & Total & 134 & 1.000 & - & - \\
\hline \multirow{2}{*}{ a. Alternative hypothesis states that the proportion of cases in the first group < .999 } \\
\hline
\end{tabular}

The Binomial Test in Table 1 revealed that the proportion (0.082) of pregnant women who were really having Asymptomatic bacteriuria was very significant since the p-value $(0.000)$ which is less than 0.05 . This, therefore, means that, out of every 1000 pregnant women who were initially declared to be free from urinary tract infection Asymptomatic bacteriuria, 82 of them were actually having Asymptomatic bacteriuria at Akuapem North District at 95\% confidence level. 
Table 2. Isolated Bacteria from Asymptomatic Bacteriuria

\begin{tabular}{|c|c|c|c|c|c|}
\hline \multirow[b]{2}{*}{ Bacteria isolated } & E. coli & Klebsiella spp & Proteus spp & Staph. aureus & Total \\
\hline & $\mathrm{n}(\%)$ & $\mathrm{n}(\%)$ & $\mathrm{n}(\%)$ & $\mathrm{n}(\%)$ & $\mathrm{n}(\%)$ \\
\hline Total bacteria isolated & $7(63.6)$ & $2(18.2)$ & $1(9.1)$ & $1(9.1)$ & $11(100)$ \\
\hline \multicolumn{6}{|l|}{ Antibiotics } \\
\hline \multicolumn{6}{|l|}{ Ampicillin } \\
\hline Sensitive & $5(71.4)$ & $2(100)$ & $0(0)$ & $0(0)$ & $7(63.6)$ \\
\hline Resistant & $2(28.6)$ & $0(0)$ & $1(100)$ & $1(100)$ & $4(36.4)$ \\
\hline \multicolumn{6}{|l|}{ Cotrimoxazole } \\
\hline Sensitive & $2(28.6)$ & $0(0)$ & $0(0)$ & $1(100)$ & $3(27.3)$ \\
\hline Resistant & $5(71.4)$ & $2(100)$ & $1(100)$ & $0(0)$ & $8(72.7)$ \\
\hline \multicolumn{6}{|l|}{ Cefuroxime } \\
\hline Sensitive & $4(57.1)$ & $1(50)$ & $0(0)$ & $0(0)$ & $5(45.5)$ \\
\hline Resistant & $3(42.9)$ & $1(50)$ & $1(100)$ & $1(100)$ & $6(54.6)$ \\
\hline \multicolumn{6}{|l|}{ Gentamicin } \\
\hline Sensitive & $6(85.7)$ & $1(50)$ & $1(100)$ & $0(0)$ & $8(72.7)$ \\
\hline Resistant & $1(14.3)$ & $1(50)$ & $0(0)$ & $1(100)$ & $3(27.3)$ \\
\hline \multicolumn{6}{|l|}{ Nalidixic Acid } \\
\hline Sensitive & $5(71.4)$ & $1(50)$ & $1(100)$ & $0(0)$ & $7(63.6)$ \\
\hline Resistant & $2(28.6)$ & $1(50)$ & $0(0)$ & $1(100)$ & $4(36.4)$ \\
\hline \multicolumn{6}{|l|}{ Nitrofurantoin } \\
\hline Sensitive & $5(71.4)$ & $2(100)$ & $1(100)$ & $1(100)$ & $9(81.8)$ \\
\hline Resistant & $2(28.6)$ & $0(0)$ & $0(0)$ & $0(0)$ & $2(18.2)$ \\
\hline \multicolumn{6}{|l|}{ Pipemidic Acid } \\
\hline Sensitive & $4(57.1)$ & $1(50)$ & $1(100)$ & $1(100)$ & $7(63.6)$ \\
\hline Resistant & $3(42.9)$ & $1(50)$ & $0(0)$ & $0(0)$ & $4(36.4)$ \\
\hline \multicolumn{6}{|l|}{ Tetracycline } \\
\hline Sensitive & $4(57.1)$ & $2(100)$ & $0(0)$ & $0(0)$ & $6(54.6)$ \\
\hline Resistant & $3(42.9)$ & $0(0)$ & $1(100)$ & $1(100)$ & $5(45.5)$ \\
\hline
\end{tabular}

Asymptomatic bacteriuria pregnant women at Akuapem Mampong and its antimicrobial susceptibility pattern. Source: Fieldwork, 2019

Table 2 showed the antimicrobial susceptibility patterns of 4 bacteria isolated from 11 pregnant women at Akuapem North District. The bacteria were three Gram-negatives namely Escherichia coli, Klebsiella spp and Proteus spp, and Staphylococcus aureus as the only Gram-positive bacteria isolated from the study. Also, from Table 2 above, the study showed that $E$. coli was the highest bacteria isolated from seven pregnant women representing 63.6\%, followed by Klebsiella spp which was isolated from 2 pregnant women representing 18.2\%. The other two bacteria were Proteus spp and
Staphylococcus aureus, which were isolated from two pregnant women representing $9.1 \%$ each.

From the study, Nitrofurantoin was the most effective antibiotic, which was sensitive to $81.8 \%$ of the bacteria isolated, followed by Gentamicin $72.7 \%$ sensitive. Cotrimoxazole was the highest resistant antibiotic to the isolated four (4) bacteria among the pregnant women in Akuapem North District, representing 72.7\%. Tetracycline was the second antibiotic with a resistance of $45.5 \%$. 
Table3. Multiple Logistic Regression Results for Factors Associated with Asymptomatic Bacteriuria

\begin{tabular}{|c|c|c|c|c|c|c|}
\hline \multirow[b]{2}{*}{ Variables } & \multicolumn{2}{|l|}{ Bacteria } & \multicolumn{2}{|c|}{ Unadjusted Model } & \multicolumn{2}{|l|}{ Adjusted Model } \\
\hline & No Growth & Growth & cOR $(95 \% \mathrm{CI})$ & P-value & aOR $(95 \% \mathrm{CI})$ & P-value \\
\hline \multicolumn{7}{|c|}{ Toilet facility } \\
\hline Private & $94(94.95)$ & $5(5.05)$ & 1.00(reference) & \multirow[t]{2}{*}{0.04} & 1.00 (reference) & \multirow[t]{2}{*}{0.06} \\
\hline Public & $29(82.86)$ & $6(17.14)$ & $3.9(1.1-13.8)$ & & $4.03(0.93-17.5)$ & \\
\hline \multicolumn{7}{|c|}{ Multiple pregnancy } \\
\hline No & $118(93.6)$ & $8(6.4)$ & 1.00(reference) & \multirow[t]{2}{*}{0.01} & 1.00 (reference) & \multirow[t]{2}{*}{0.01} \\
\hline Yes & $5(62.5)$ & $3(37.5)$ & $8.85(1.7-44.2)$ & & $9.52(1.7-51.9)$ & \\
\hline \multicolumn{7}{|c|}{ Any medical condition } \\
\hline No & $115(93.5)$ & $8(6.5)$ & 1.00 (reference) & \multirow[t]{2}{*}{0.03} & 1.00 (reference) & \multirow[t]{2}{*}{0.09} \\
\hline Yes & $8(72.7)$ & $3(27.3)$ & $5.4(1.19-24.5)$ & & $2.0(0.26-16.9)$ & \\
\hline
\end{tabular}

cOR-crude odds ratio aOR-adjusted odd ratio CI-confidence interval.

Multiple logistic regression analysis was conducted on all the associated factors that were statistically significant at 95\% CI and P-value $\leq$ 0.05 at the bivariate level. These factors were toilet facility, multiple pregnancies, and any medical condition. Out of the three associated factors that were significantly associated with at t Asymptomatic bacteriuria he bivariate analysis, only one was statistically significant and strongly associated with the development of Asymptomatic bacteriuria at the multiple logistic regression analysis levels (P-value $\leq$ 0.05). This is shown on Table 3 above.

The study investigated the proportion of Asymptomatic bacteriuria among a study population of one 134 pregnant women from six selected health facilities in Akuapem North District during a period of May to July 2019. Urine specimens were cultured from pregnant women whose initial results with routine urine examination were negative for protein, nitrite, leucocytes, and pus cells less than 5/ HPF. The results of the study showed that 11 out of one hundred and thirty-four 134 pregnant women had had ASB giving a proportion of $8.2 \%$ (4.314.6). The prevalence is almost close to similar work done by [11]. This study is in agreement with what several researchers said about the prevalence of Asymptomatic bacteriuria among pregnant women that is from $2.5 \%$ to over $10 \%$ [12].
In contrast to this study, the study done in Nigeria by [13] had a much higher prevalence of $86.6 \%$, which may be due to the difference geographical area of the study population or the screening method used in selecting the participants. Asymptomatic bacteriuria rarely causes serious problems however, in pregnancy, if this condition is left untreated, more than $30 \%$ of the pregnant women will develop serious complications [14].

From the Binomial Test in Table 1 show that the proportion 11/134 (0.082) of pregnant women who were really having Asymptomatic bacteriuria was very significant since the $p$-value $(<0.001)$ is less than 0.05. This, therefore, means that, out of every 1000 pregnant women who were initially declared free from urinary tract infection with the routine urine examination technique used in Akuapem North District among the participants, 82 will have Asymptomatic bacteriuria, and out of that, more than 25 of them will develop serious complications. Some of these consequences of Asymptomatic untreated bacteriuria in pregnant women may lead to pyelonephritis, low birth weight, premature labor, eclampsia, premature rupture of the membrane, mental retardation, fatal death, pregnancy-induced hypertension, anaemia [15]. This can be a great worry to families since more resources will be spent to treat these conditions or even spend the whole 
lifetime looking after a human being from infancy through adulthood to old age if he/ she has developed a mental condition. Life can also be lost since this condition can result into fatality on the part of either child or mother.

According to [16], in Turkey, the prevalence of Asymptomatic bacteriuria was $8.5 \%$ which has a difference of $0.3 \%$ from this study. Similar studies were conducted in the same country Ghana but in different geographical regions. These studies were conducted in Ashanti Region at Komfo Anokye Teaching Hospital, Kumasi by [10] and had a prevalence of 7.2\%. At Korlebu Teaching Hospital in the Greater Accra Region, the capital city of Ghana, the prevalence of Asymptomatic bacteriuria was 5.5\% [7]. This research was also carried out at Akuapem North District from May-July, 2019 in the Eastern Region of Ghana and had a result of $8.2 \%$ prevalence of Asymptomatic bacteriuria among pregnant women. These variations in prevalence can be attributed to several factors, some of them are sociodemographic factors, environmental factors, clinical/pregnancy history, and health facilities. Four different types of bacteria were isolated from the study. These were E. coli 7(63.6\%), Klebsiella spp 2(18.1\%), Proteus spp $1(9.1 \%)$ and Staphylococcus aureus 1(9.1\%).

Comparing the study to similar studies done in Ghana, the commonest bacteria isolated was in line with the one conducted by [10] at Komfo Anokye Teaching Hospital, Kumasi, which had E. coli- 6(37.5\%). In Greater Accra Region, [7] had Enterococcus spp of $4(26.7 \%)$ as the common bacteria isolated at the Korle-Bu Teaching Hospital. Studies were done in different countries all confirmed $E$ coli to be the most causative bacteria causing Asymptomatic bacteriuria among pregnant women. This can be affirmed by [17] in Babol city, [18], Jahrom, [19] in Tanzania [20] in Yemen [21] in Gorgan, and all had E. coli as the most causative bacteria in their studies. This is consistent with the work done at Akuapem North District. Antibiotics are among the most frequently prescribed types of medication during pregnancy and lactation [22].
The study showed the antimicrobial susceptibility patterns of four different types of bacteria isolated from eleven pregnant women. The bacteria were three Gram-negatives: Escherichia coli, Klebsiella spp and Proteus spp, and Staphylococcus aureus, the only Grampositive bacteria isolated from the study.

Table 2 showed E. coli was the most predominant bacteria isolated from 7 pregnant women representing $63.6 \%$, followed by Klebsiella spp. it was isolated from 2 pregnant women representing $18.2 \%$. The other two bacteria were Proteus spp and Staphylococcus aureus. Proteus spp was isolated from one pregnant woman, and Staphylococcus aureus was from another pregnant woman representing 9.1\% each.

From the study, Nitrofurantoin was the most effective antibiotic, which was $81.8 \%$ sensitive to the bacteria isolated. This was in agreement to the study done by [7] and went further to explain that antibiotics is not commonly used for the treatment of UTI in Ghana; therefore, their abuse is limited. From this study, Gentamicin was $72.7 \%$ sensitive to the isolated bacteria, and from the researcher's point of view, this antibiotic is an injectable; therefore, the use of it might be limited unless prescribed by a clinician or a pharmacist and also the pain in injecting one's self with a needle.

Cotrimoxazole was the highest resistant antibiotic to the isolated four bacteria among the pregnant women in Akuapem North District, representing $72.7 \%$. It is very common in Ghana, and both the injection and the tablet, so the abuse of it is high. Cefuroxime is also gradually becoming resistant since this is given to pregnant women to treat urinary tract infections [23]. When routine urine examination results suggest urinary tract infection, it must be confirmed by culture and sensitivity to know its susceptibility pattern and epidemiology. Epidemiological studies carried out among pregnant women in different populations worldwide have identified a diverse range of factors for asymptomatic bacteriuria [24]. The result of this study showed 
that there were no statistically significant associations with the development of Asymptomatic bacteriuria between most of the factors. [7] reported, the prevalence of Asymptomatic bacteriuria was associated with sexual activity during pregnancy, but not with sexual frequency, their finding affirmed in the current study.

The frequency of sexual intercourse per week was not statistically significant (p-value 0.353 ). At the bivariate level, only four of these factors were statistically significant at $95 \% \mathrm{CI}$ and Pvalue $\leq 0.05$. The results from the analysis indicate that toilet kind ( $\mathrm{p}$-value $=0.03$ ), multiple pregnancy $(\mathrm{p}$-value $=0.01)$, family history of medical condition ( $p$-value $=0.04$ ) and UTI previous experience $(\mathrm{p}$-value $=0.03)$ were associated with Asymptomatic bacteriuria. This means that there is a possibility of pregnant women having Asymptomatic bacteriuria based on these factors.

According to [25], women who have many children before the present pregnancy and it has been reported that multiparity is associated with Asymptomatic bacteriuria. In this study, the number of births was not statistically significant, but it was multiple pregnancies that were strongly associated with 9.5 folds greater odds of getting Asymptomatic bacteriuria compared to those with no multiple pregnancies in both bivariate and multivariate analysis 8.9 and 9.2 respectively.

\section{Conclusion}

The prevalence of asymptomatic bacteriuria among pregnant women is $8.2(4.3 \%-14-6 \%)$ at Akuapem North District. E. coli was the most predominate bacteria isolated with $63.6 \%$. Quantitative urine culture is the ideal test for the detection of asymptomatic bacteriuria.

The culture method helps to identify the bacteria and per its susceptibility pattern in order to reduce the antibiotics resistance, which has now become a public health problem globally. Early detection and treatment are essential to safeguard the health of the mother and fetus. In this study, Nitrofurantoin was the most sensitive with a percentage of 81.8 , and Cotrimoxazole was the most resistant of $72.7 \%$. Screening of Asymptomatic bacteriuria with the gold standard will help in knowing the bacteria causing the infection and deciding the best choice of antibiotics treatment.

\section{Recommendation}

Medical laboratories in the district need to be upgraded to enable them to screen for Asymptomatic bacteriuria for all pregnant women with a more sensitive technique instead of the routine urine examination, which is not sensitive in detecting Asymptomatic bacteriuria among pregnant women.

\section{Conflict of Interest}

The authors declare that they have no competing interests.

\section{Acknowledgement}

We will like to express our gratitude to all medical and non-medical staff of the various health facilities for their contribution towards this work. 


\section{References}

[1] Szweda, H., \& Jóźwik, M. J. D. P. M. (2016). Urinary tract infections during pregnancy-an updated overview. 20(4), 263-272.

[2] Scort, JR., E.D.whitefeaded and H.M Naghes, 1990. Dan Forty Obstertrics and Gynaecology.6th Edn, McGraw Hill Boston,pp:60-80.

[3] Ortega-González, Y., \& Castro-Diaz, D. J. C. B. D. R. (2014). Antibiotic considerations for urinary tract infections in pregnancy. 9(3), 167-174.

[4] Samuel, O., Victoria, O., \& Ifeanyi, O. J. U. J. o.

C. M. (2016). Prevalence of asymptomatic bacteriuria among the pregnant women receiving antenatal care at federal medical centre Owerri, Nigeria. 4(1), 1-5.

[5] Akerele, P. A., F. Okonofua, J , \& Gynaecology. (2001). Prevalence of asymptomatic bacteriuria among pregnant women in Benin City, Nigeria. Journal of Obstetrics Gynaecology, 21(2), 141-144.

[6] Ugbogu, O. (2007). Asymptomatic bacteriuria among pregnant women in Abakaliki, Ebonyi State Nigeria. Med. Sci., 7(4), 698-700.

[7] Labi, A., Yawson, A., Ganyaglo, G., \& Newman, M. (2015). Prevalence and associated risk factors of asymptomatic bacteriuria in ante-natal clients in a large teaching hospital in Ghana. Ghana medical journal, 49(3), 154-158.

[8] Blomberg, B., Olsen, B. E., Hinderaker, S. G., Langeland, N., Gasheka, P., Jureen, R., Midtvedt, T. (2005). Antimicrobial resistance in urinary bacterial isolates from pregnant women in rural Tanzania: implications for public health. Scandinavian journal of infectious diseases, 37(4), 262-268.

[9] http://www.easternregion.gov.gh/index.php/profi le/.

[10] Turpin, C., Minkah, B., Danso, K., \& Frimpong, E. J. G. m. j. (2007). Asymptomatic bacteriuria in pregnant women attending antenatal clinic at komfo anokye teaching hospital, Kumasi, ghana. 41(1), 26.

[11] Debebe, S. (2005). Asymptomatic Bacteriuria in Pregnant Women in Harar, South Eastern Ethiopia. Addis Ababa University.

[12] Abdullahi, H. I., \& Thairu, Y. J. I. J. o. P. (2015). Asymptomatic bacteriuria among pregnant women attending antenatal: evaluation of screening test. 5(8), 41-47.
[13] Schnarr, J., \& Smaill, F. J. E. j. o. c. i. (2008). Asymptomatic bacteriuria and symptomatic urinary tract infections in pregnancy. 38, 50-57.

[14] Mohamed, N. R., Omar, H. H. H., \& Abd-Allah, I. M. J. I.-J. (2017). Prevalence and Risk Factors of Urinary Tract Infection among Pregnant Women in Ismailia City, Egypt. 6(3), 62-72.

[15] Çelen, Ş., Oruç, A. S., Karayalçin, R., Saygan, S., Ünlü, S., Polat, B., . . . gynecology. (2011). Asymptomatic bacteriuria and antibacterial susceptibility patterns in an obstetric population. 2011.

[16] Amiri, M., Lavasani, Z., Norouzirad, R., Najibpour, R., Mohamadpour, M., Nikpoor, A. R., . . . Marzouni, H. Z. (2015a). Prevalence of urinary tract infection among pregnant women and its complications in their newborns during the birth in the hospitals of Dezful city, Iran, 2012-2013. Iranian Red Crescent Medical Journal, 17(8).

[17] Emamghorashi, F., Mahmoodi, N., Tagarod, Z., \& Heydari, S. T. (2012). Maternal urinary tract infection as a risk factor for neonatal urinary tract infection. Iranian journal of kidney diseases, 6(3), 178.

[18] Masinde, A., Gumodoka, B., Kilonzo, A., \& Mshana, S. (2009). Prevalence of urinary tract infection among pregnant women at Bugando Medical Centre, Mwanza, Tanzania. Tanzania journal of health research, 11(3).

[19] Abdullahi, H. I., \& Thairu. (2015). Asymptomatic bacteriuria among pregnant women attending antenatal: evaluation of screening test. IOSR Journal of Pharmacy, 5(8), 41-47.

[20] Mobsheri, E., Tabbraei, A., Ghaemei, E., Moujerlou, M., Vakili, M., Dastforooshan, M., \& Gholamei, S. (2002). Distribution of Asymptomatic Bacteriuria in Pregnant Women Referring to Dezyani Hospital in Gorgan.

[21] Mobsheri, E., Tabbraei, A., Ghaemei, E., Moujerlou, M., Vakili, M., Dastforooshan, M., \& Gholamei, S. (2002). Distribution of Asymptomatic Bacteriuria in Pregnant Women Referring to Dezyani Hospital in Gorgan.

[22] Nahum, G. G., Uhl, K., Kennedy, D. L. J. O., \& Gynecology. (2006). Antibiotic use in pregnancy and 
lactation: what is and is not known about teratogenic and toxic risks. 107(5), 1120-1138.

[23] Sorlozano, A., Jimenez-Pacheco, A., del Castillo, J. d. D. L., Sampedro, A., Martinez-Brocal,

A., Miranda-Casas, C., Gutiérrez-Fernández, J. (2014). Evolution of the resistance to antibiotics of bacteria involved in urinary tract infections: a 7-year surveillance study. American journal of infection control, 42(10), 1033-1038.

[24] Tellapragada, C., Eshwara, V. K., Bhat, P., Acharya, S., Kamath, A., Bhat, S., Health, P. (2016).
Risk factors for preterm birth and low birth weight among pregnant Indian women: a hospital-based prospective study. Journal of Preventive Medicine, 49(3), 165.

[25] Andabati, G., \& Byamugisha, J. J. A. h. s. (2010). Microbial aetiology and sensitivity of asymptomatic bacteriuria among ante-natal mothers in Mulago hospital, Uganda. 10(4). 